Revista Española de Antropología Americana ISSN: 0556-6533

https://doi.org/10.5209/reaa.66520

\title{
Tasiilaq: política, identidad y arte en la costa este de Groenlandia
}

\author{
Carlos Moral García ${ }^{1}$
}

Recibido: 5 de septiembre de 2017 / Aceptado: 23 de febrero de 2019

Resumen. Este artículo analiza y visibiliza la situación de la costa este de Groenlandia en el contexto de descolonización e independencia con respecto a Dinamarca. Como parte fundamental de la investigación, se analizan informaciones etnográficas recogidas en Tasiilaq, la ciudad más grande de esta región. Además, se realiza un repaso histórico del proceso colonial y la consecución de la autonomía política, así como el avance groenlandés hacia su emancipación. De este modo, se puede apreciar la importancia de la política en los procesos de identificación cultural y producción artística.

Palabras Clave: Groenlandia; Tasiilaq; política; identidad; arte; inuit.

\section{[en] Tasiilaq: Politics, Identity and Arts in the East Coast of Greenland}

\begin{abstract}
This paper analyses and makes visible the situation of the Greenland's East Coast in the decolonization and independence in relation to context. As main part of this research, it is analyzed some ethnographic information collected in Tasiilaq, the biggest city in this area. In addition, it is reviewed the historical process of colonial period and the consecution of the autonomic Home Rule, as well the Greenlandic progress to emancipation. This way, it is possible to value the importance of the politics in the cultural identification and artistic creation process.
\end{abstract}

Keywords: Greenland; Tasiilaq; politics; identity; arts; inuit.

Sumario. 1. Introducción. 2. Tasiilaq-Ammassalik: una comunidad en la costa este de Groenlandia. 3. Groenlandia: de la colonia a la autonomía. 4. Caminando hacia la independencia. 5. ¿Un único modelo de independencia? 6. Arte tradicional: comercio e identidad. 7. Conclusiones. 8. Referencias.

Cómo citar: Moral García, Carlos. 2019. «Tasiilaq: política, identidad y arte en la costa este de Groenlandia». Revista Española de Antropología Americana 49: 87-108.

\section{Introducción}

Tasiilaq, con una población total en 2017 de 2.030 personas $^{2}$ y antes conocida como Ammassalik (Angmagssalik), es la localidad más grande y poblada de la costa este de Groenlandia (Figura 1; Figura 2). Sin embargo, se ubica políticamente en el municipio (Kommune/Kommuneqarfik) de Sermersooq (Figura 3), operativo desde 2009 y que incluye también parte de la costa oeste, en concreto la región correspondien-

\footnotetext{
1 Universidad Complutense de Madrid. carmoral@ucm.es

2 Información oficial facilitada por la delegación local en Tasiilaq del Kommuneqarfik Sermersooq a fecha de 28 de junio de 2017. La cifra estimada por City Population para el 1 de enero de 2019 es de 2.063 personas (http:// citypopulation.de/Greenland.html).
} 


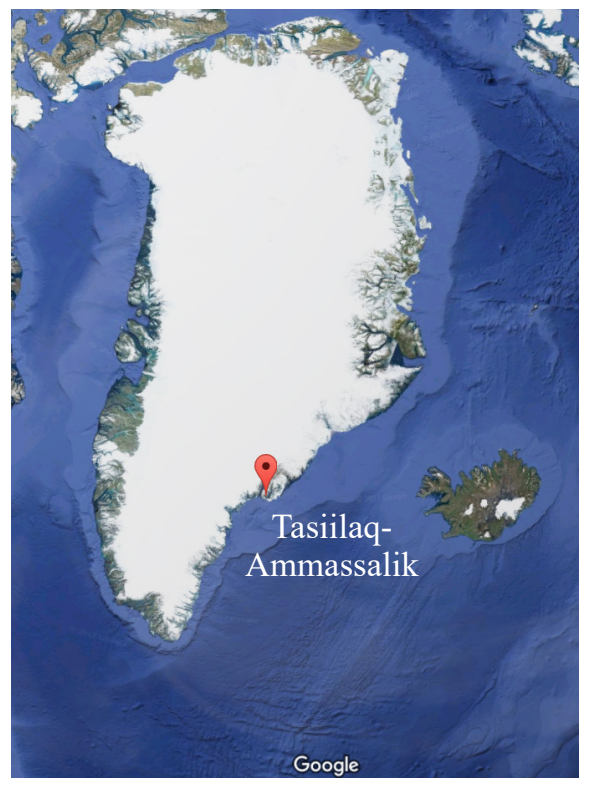

Figura 1. Ubicación de Tasiilaq-Ammassalik en la costa este de Groenlandia-Kalaallit Nuunat (www.google.es/maps).

Figura 2. Vista de Tasiilaq-Ammassalik desde el interior (fotografía de Carlos Moral García).

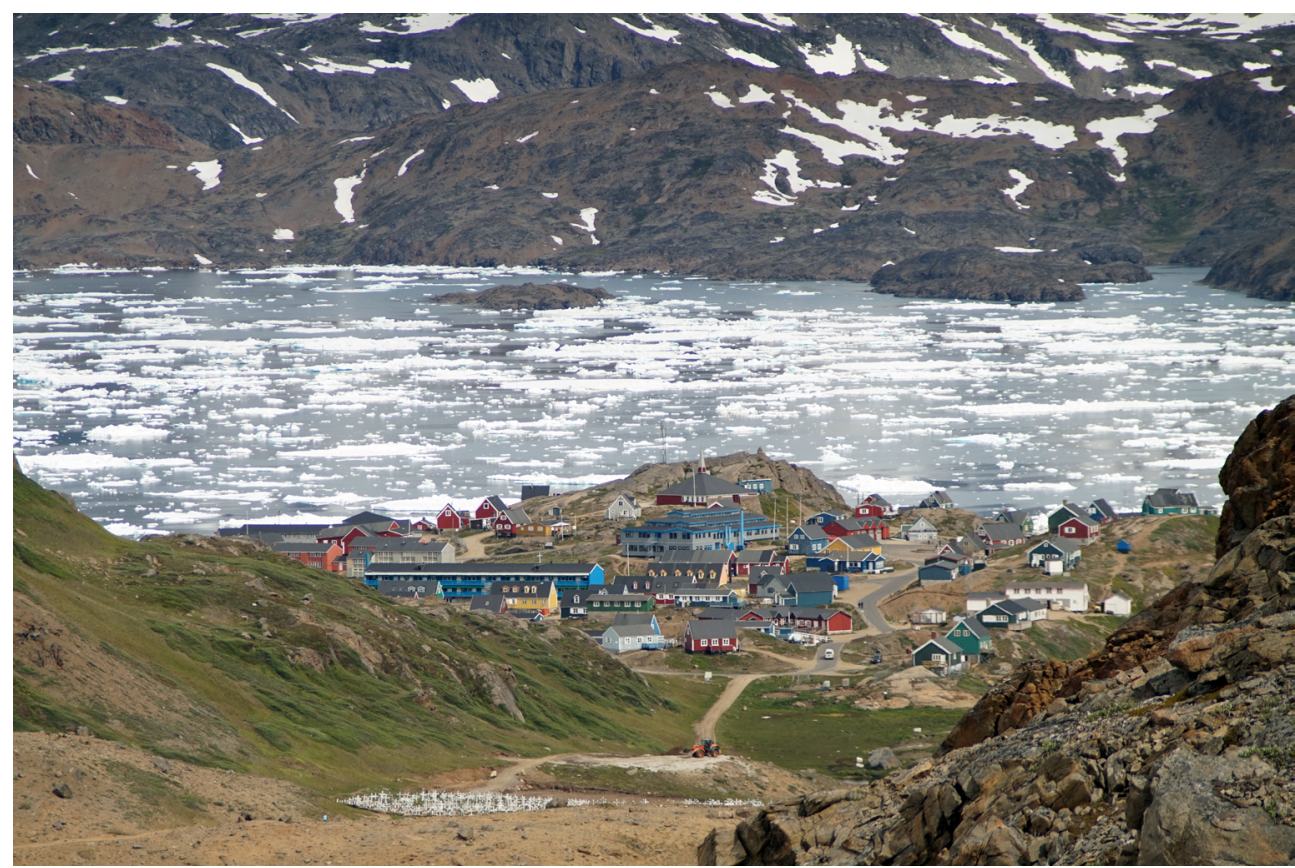

te a Nuuk, cabecera municipal y capital del territorio autónomo groenlandés, con 17.984 habitantes estimados a 1 de enero de 2019 (City Population). Esto genera en su población ciertas discrepancias e inconformidades al respecto de la organización territorial, lo que se podrá ver más adelante.

La base de esta investigación es la información etnográfica recogida durante la campaña etnográfica realizada durante los meses de junio y julio de 2017 en Tasiilaq. 
Se trata de un total de 13 informantes (Cuadro 1) $)^{3}$, la mayoría de ascendencia inuit y nativos de la costa este de Groenlandia. También se han tenido en consideración testimonios de daneses o inuit de la costa oeste residentes en la localidad, así como de personas nacidas en Tasiilaq de ascendencia no inuit.

Cuadro 1. Caracterización de los informantes (ordenados según la fecha en que se contactó con ellos por primera vez).

\begin{tabular}{llllc}
\hline Informantes & Género & Edad & Nacionalidad (Región) & $\begin{array}{c}\text { Ascendencia } \\
\text { etnocultural }\end{array}$ \\
\hline Informante 1 & Varón & 51 & Groenlandés (Costa Este) & Inuit \\
Informante 2 & Varón & 50 aprox. & Groenlandés (Costa Este) & Inuit \\
Informante 3 & Varón & $40-50$ aprox. & Groenlandés (Costa Este) & Inuit \\
Informante 4 & Varón & 60 aprox. & Groenlandés (Costa Este) & Inuit \\
Informante 5 & Mujer & $50-60$ aprox. & Groenlandesa (Costa Este) & Inuit \\
Informante 6 & Mujer & $25-30$ aprox. & Danesa (Copenhague) & No inuit \\
Informante 7 & Varón & 56 & Groenlandés (Costa Este) & Inuit \\
Informante 8 & Mujer & 30 aprox. & Groenlandesa (Costa Este) & No inuit \\
Informante 9 & Varón & 50 aprox. & Groenlandés (Costa Este) & Inuit \\
Informante 10 & Varón & 60 aprox. & Groenlandés (Costa Este) & Inuit \\
Informante 11 & Mujer & 40 aprox. & Groenlandesa (Costa Este) & Inuit \\
Informante 12 & Varón & 50 aprox. & Groenlandés (Costa Este) & Inuit \\
Informante 13 & Mujer & 40 aprox. & Groenlandesa (Costa Oeste) & Inuit \\
\hline
\end{tabular}

En este trabajo se presenta, tras una caracterización de Tasiilaq, la situación política de Groenlandia -55.992 habitantes a 1 de enero de 2019 (Statistics Greenland)como región autónoma de Dinamarca, en vías de una independencia democrática. Para ello se repasan los antecedentes históricos y el devenir contemporáneo de toda la isla para comprender mejor el caso concreto de la costa oriental. Se utilizan diferentes obras bibliográficas de referencia, como los recientes trabajos de Francesc Bailón $(2012,2013,2015)$, pero también obras anteriores que permitan reflejar las particularidades culturales de esta región a lo largo del tiempo, como el Volumen 5 del Handbook of North American Indians (Damas 1984).

De este modo se pueden llegar a esbozar algunos rasgos generales de las relaciones políticas de la localidad con el municipio y el gobierno autonómico, así como de la percepción que tienen sus poblaciones de las mismas. Esto facilita el conocimiento de la autosignificación identitaria groenlandesa y de la propia costa este pues, como se verá más adelante, se perciben como realidades claramente diferenciadas de la identidad danesa e incluso entre ellas.

Este estudio se detiene también en cómo esto se manifiesta y refleja en el arte tradicional, así como en el cambio funcional de ciertas obras artísticas. Objetos de diferentes orígenes y significados se han ido incorporando como producción artística, un elemento que permite obtener ingresos a partir del turismo y, simultáneamente, la presentación de la propia comunidad al observador externo. Por ello, la organización política, el discurso identitario y las manifestaciones artísticas caminan de la mano en un contexto complejo en transición desde el modelo tradicional a la contempora-

\footnotetext{
3 Con objeto de mantener el anonimato de las personas que participaron como informantes en la investigación, se ha optado por el uso de la expresión «Informante» cuando se hace referencia a ellos en el texto; el Cuadro 1 ofrece una caracterización genérica de cada uno de ellos.
} 
neidad global, desde el pasado groenlandés, como parte de Dinamarca, a un modelo de independencia estatal, pasando por el actual modelo autonómico.

\section{Tasiilaq-Ammassalik: una comunidad en la costa este de Groenlandia}

Tasiilaq, antes conocido como Ammassalik, es la localidad más poblada de la costa oriental de Groenlandia. Antes de entrar de lleno en la exposición y análisis de las informaciones etnográficas recogidas, conviene hacer una breve contextualización histórica para conocer algunas de las características específicas que influyen en su desarrollo actual.

Esta región insular, cuajada de irregulares montañas, bahías y fiordos, que se encuentra en una latitud norte de 65²0' (Petersen 1984a: 622; Bailón 2015: 275), recibía su nombre del capelín o ammasat (Mallotus villosus) y sus habitantes eran denominados ammassalimiut (Bailón 2012: 82-83). En esta área existen además numerosos mamíferos marinos, como la foca anillada (Phoca hispida), foca de casco (Cystophora cristata), foca barbuda (Erignatus barbatus) y más raramente la morsa (Odobenus rosmarus). También se pueden encontrar cetáceos como el narval (Monodon monoceros), beluga (Delphinapterus leucas) (Petersen 1984a: 623) y zifio calderón boreal (Hyperoodon ampullatus), con incursiones esporádicas en los fiordos, pero sobre todo en mar abierto, del mismo modo que las ballenas barbadas, como el rorcual aliblanco (Balaenoptera acutorostrata) (Informante 12).

La población nativa, heredera directa de la cultura Dorset en muchos aspectos, no fue contactada hasta 1884, con la expedición del explorador danés Gustav Frederik Holm, aunque antes, en 1823, fueron avistados por Douglas Clavering y Edward Sabine. Tal y como se verá más adelante, presenta una cronología mucho más tardía que los procesos de colonización. Esta área había permanecido aislada de las colonizaciones europeas e incluso del contacto con inuit de la costa occidental durante largo tiempo. No en vano se conoce a la región como Tunu, «el otro lado, la espalda» (Robert-Lamblin 1986: 94; Bailón 2012: 81-83, 2015: 274-281). El agua de la corriente fría del Labrador arrastra grandes bloques de hielo que dificultan la comunicación marítima, incluso en verano, pues pueden colapsar la salida de las bahías y fiordos (Bailón 2015: 275; Informante 12).

En 1892 la zona volvió a ser visitada por Carl Hartvig Ryder. En 1894, Johan Petersen y el reverendo Frederik Carl Peter Rüttel fundaron la pequeña colonia en donde hoy se encuentra Tasiilaq, por lo que se considera la fecha de nacimiento de la localidad. Se creó un puesto comercial danés en torno al cual se fue concentrando la población local y en 1895 se ofició el primer servicio religioso cristiano. Los primeros bautismos tuvieron lugar en 1899 y el primer matrimonio cristiano en 1900 . En 1904 Rüttel abandonó la isla, mientras que la administración danesa instaló la primera escuela en la región (Christensen y Ebbesen 1984: 6-8; Robert-Lamblin 1986: 94; Bailón 2012: 83, 2015: 280). Aunque en un primer momento se trató de limitar el acceso a los productos europeos por la vía legal, en 1905 se levantaron dichas prohibiciones y desarrollaron la misma dependencia con respecto a algunos de ellos que el resto de poblaciones groenlandesas, con conflictividades similares que se mostrarán en las páginas siguientes (Bailón 2015: 280).

Durante el siglo XX la población de esta región aumentó considerablemente, en gran parte debido a la reducción de la mortalidad infantil, y se fueron asumiendo las 
formas de vida y urbanismo de corte danés que se habían ido implantando en el resto de Groenlandia. Durante los años 40 y 50 las casas prefabricadas se convirtieron en la construcción de residencia más habitual, y la dieta se fue modificando con el acceso a productos occidentales por vía comercial (Bailón 2015: 281). A pesar de que la caza y la pesca continúan presentes en la vida de esta región, la mayoría de las familias dependen de los ingresos procedentes de otras profesiones o de los subsidios estatales, sobre todo en los centros de población de mayor tamaño (Bailón 2012: 84, 2015: 281; Informante 6; Informante 8).

Por otro lado, se trata de la región groenlandesa en la que los subsidios y ayudas autonómicas son menores de toda la isla, lo que hace de ella una de las más pobres y con más bajo nivel de vida. Gran parte de las viviendas no tienen suministro de agua corriente (Petersen 1984b: 721; Bailón 2015: 282) y parece que se incentiva la ocupación de edificios de apartamentos o adosados frente a los edificios unifamiliares. Las condiciones climáticas y marítimas limitan mucho el acceso de mercancías e incrementan sus precios, ya que el primer barco de suministro suele llegar a Tasiilaq en mayo o incluso junio, y el último de la temporada en noviembre, u octubre en el peor de los casos (Bailón 2015: 282; Informante 6; Informante 8; Informante 12). Dado el largo periodo entre el último y el primer suministro, la mayoría de los productos deben ser imperecederos, ya sea por ser secos, enlatados o congelados. Los productos frescos de tipo occidental, como frutas, verduras, huevos o leche, deben ser importados por vía aérea durante el invierno. Esta situación hace que el precio de todos los productos aumente en estas fechas, pero sobre todo los segundos, que pueden llegar a triplicar o cuadruplicar su precio de verano o incluso, simplemente, no estar disponibles (Informante 6; Informante 8).

La pesca industrial de tipo comercial que existe en la costa oeste es prácticamente nula en esta región y la caza de focas se encuentra muy limitada debido a la imposibilidad de exportarla a la Unión Europea. Esta situación hace que el turismo esté revelándose como la principal fuente de ingresos extranjeros, pues, además de los servicios de los que disfruta, consume gran parte de los productos artísticos y artesanales (Petersen 1984b: 723; Bailón 2012: 84, 2015: 283). Por estos motivos se analizarán específicamente estos aspectos más adelante, ya que son fundamentales en cuestiones económicas e identitarias. Sin embargo, antes es conveniente conocer el desarrollo histórico de esta isla en un contexto de colonización y globalización dinámico y complejo, pues solo así se puede comprender la construcción de la identidad nacional groenlandesa.

\section{Groenlandia: de la colonia a la autonomía}

Groenlandia o Kalaallit Nunaat, ya que esta es la denominación en lengua kalaallisut $\mathrm{o}$ groenlandés, ha vivido numerosos cambios políticos y territoriales durante el último siglo. Quizás el más llamativo de ellos sea su proceso de descolonización y emancipación con respecto al Reino de Dinamarca.

Esta isla, reclamada como colonia desde el siglo XVI, vio incrementadas las relaciones con la metrópolis sobre todo a partir del siglo XVIII. Esto se debe en gran medida a la misión religiosa proyectada por Hans Egede en 1710 para la costa oeste, 174 años antes del contacto con las poblaciones del litoral oriental. En 1724 se realizaron los primeros bautismos de población indígena, mientras se establecían 
puestos comerciales y balleneros que pudieran sustentar tamaña empresa evangelizadora e incrementar los intereses monárquicos en ella. Sin embargo, pronto surgieron las desavenencias entre religiosos y comerciantes, pues los lugares elegidos para la evangelización no eran los más propicios para la compra y venta de materiales nativos. Sin entrar en demasiados detalles, es importante saber que los objetivos económicos primaron sobre los espirituales (Gad 1984: 557-558; Kaalund 2001: 206; Bailón 2012: 107-108; Domínguez-Solera 2014: 13).

El cada vez más intenso contacto con las poblaciones europeas por parte de los inuit, propició la introducción de nuevas tecnologías para la caza y el progresivo cambio en ciertas dinámicas de subsistencia hacia una mayor dependencia exterior. Esta situación hizo que en Groenlandia se acusase en gran medida cualquier cambio económico y político que se produjera en Dinamarca. Con el fin de reducir dicha dependencia se aplicaron ciertas políticas proteccionistas y aislacionistas desde finales del siglo XVIII. Entre ellas estaba la obligatoriedad del modelo de subsistencia cazador para la población inuit, lo que no implica el uso de técnicas tradicionales ya que las armas de fuego habían pasado a ser un elemento fundamental. También se limitaban las expediciones extranjeras más allá de aquellas con intereses puramente científicos (Bailón 2012: 108-111).

Con la llegada del siglo XX aparecieron también los primeros planteamientos a favor de un cambio en el sistema colonial, cada vez más obsoleto. Con la ley de administración de 1908 se formaron consejos municipales y autonómicos autosuficientes, de manera que la gestión administrativa y económica era menos dependiente del gobierno metropolitano. No obstante, el comienzo del siglo venía acompañado de algunos conflictos internacionales, pues Noruega, tras independizarse de Suecia en 1905, reclamaba su derecho de explotación sobre Groenlandia. En 1933 el Tribunal Internacional de La Haya confirmó la soberanía danesa sobre toda la isla. Algo después, la Segunda Guerra Mundial aisló Dinamarca de sus territorios groenlandeses y Estados Unidos decidió instalar varias bases aéreas en ellos. Al finalizar el conflicto, el gobierno danés mantuvo su cooperación y se incorporó a la OTAN. De este modo, se reconocía el derecho de uso de varias bases aéreas, de las cuales solo Thule (Pituffik) sigue estando bajo control de Estados Unidos (Gad 1984: 570-574; Bailón 2012: 112-113).

Tras esta serie de cambios políticos y dadas las dificultades económicas que el aislamiento y las medidas proteccionistas habían causado, en 1945, la población nativa solicitaba el cambio del sistema colonial hacia un sistema de inversión modernizadora. En 1948, Hans Hedtoft, primer ministro danés, viajó a Groenlandia para estudiar el caso. A su retorno, se encomendó a una comisión formada por cuatro daneses y cuatro groenlandeses la elaboración de un informe a raíz de la documentación recogida. En él se sugería la eliminación del monopolio comercial y la reforma administrativa para unificarse en un solo Consejo Nacional. Con esto se constituyó el plan de acción decenal que se denominó G-50. En 1952, se aprobaba en el Consejo Nacional un proyecto de estatuto en sustitución del existente para la Groenlandia colonial. En 1953 fue aprobado por Dinamarca, que accedió a tener dos representantes groenlandeses en el Parlamento (Folketing) (Gad 1984: 574; Kleivan, Helge 1984: 700-702; Bailón 2012: 113-114). Con la reforma constitucional de ese mismo año, Groenlandia dejaba de ser una colonia y se incorporaba como una región más de Dinamarca. Se implantaron numerosos servicios sanitarios y de asistencia social, con un notable aumento de las infraestructuras. También se tendió a la concentración 
de la población en ciudades de mayor tamaño, lo que generó un progresivo abandono del modelo de caza tradicional y un mayor desempleo (Bailón 2012: 113-114, 2013: 48).

Pese a tener efectos muy positivos en algunos aspectos, los factores negativos fueron muy acusados y se generó un aumento extraordinario de la dependencia de los subsidios estatales, el alcoholismo y el número de suicidios, muchas veces producidos por la profunda anomia de las poblaciones movilizadas. Esto llevó a los políticos groenlandeses a presentar, en 1964, un nuevo plan decenal, el G-60, para implementar ciertos servicios sociales y reducir las desigualdades económicas entre la población de origen danés y la población inuit. A partir de 1967, el Consejo Nacional de Groenlandia eligió a su propio presidente. En 1971, con la elección de Lars Emil Johansen y Jonathan Motzfeldt como representantes en la cámara parlamentaria danesa aumentaron las críticas hacia una educación demasiado «danesificada» y a la concentración urbana. El modelo tradicional estaba desapareciendo y los modelos de pesca a mayor escala implementados en las ciudades no eran lo bastante productivos para emplear y mantener a tanta población (Kleivan, Helge 1984: 703-705; Bailón 2012: 115-117).

En 1972 el Consejo solicitó al gobierno danés la posibilidad de un mayor control y participación en el desarrollo de Groenlandia. La adhesión de Dinamarca a la CEE en 1973, previo referéndum, pese a que la gran mayoría del pueblo groenlandés votó en su contra, generó una intensa actividad política que reivindicaba una mayor gestión de los recursos por parte de la población autóctona. En 1975 la Reforma Municipal concedía a los consejos regionales un mayor control y gestión de los asuntos locales (Kleivan, Helge 1984: 715; Bailón 2012: 117-118).

En 1977 Groenlandia participó en la primera Inuit Circumpolar Conference (ICC), celebrada en Barrow (Alaska), en la que se reunieron representantes inuit de Alaska, Canadá y Groenlandia. En 1978, tras las recomendaciones de una comisión para estudiar el caso groenlandés, el Folketing danés aprobó en noviembre la Ley de Autonomía de Groenlandia. De este modo el 17 de enero de 1979, se celebró un referéndum, con una participación del $63 \%, 12.754$ a favor y 4.705 en contra de la independencia. El 1 de mayo de 1979 Groenlandia quedaba constituida como autonomía política, en un régimen de semi-independencia (Bailón 2012: 117, 2015: 390).

\section{Caminando hacia la independencia}

Una vez establecida la autonomía, el Nuna asiilasooq, himno usado por la población groenlandesa, se reconoció por parte del gobierno, así como el kalaallisut como lengua cooficial junto al danés. Además, se reconocieron tres dialectos más, el inughuaqtun, del noroeste; el tunumiisut, del este; y el kitaamiutut, del oeste, lo que refleja las variaciones culturales existentes dentro de una población inuit, por otra parte, con rasgos similares entre sí. A partir de 1979 comenzó a aplicarse lo que se conoce como ideología de la «groenlandización», en contraposición a la «danesificación» anterior que se podía apreciar claramente en el sistema educativo y la organización sociocultural. Mientras, se reivindicó el uso de Kalallit Nunaat (tierra de los groenlandeses) en sustitución de Groenlandia como referencia a este territorio (Bailón 2012: 150, 2013: 31, 2015: 390). 
El 23 de febrero de 1982 se produjo en Groenlandia un referéndum democrático para escindirse de la Comunidad Económica Europea, un acontecimiento histórico y legal sin precedentes cuya repercusión aún está por definirse. E1 53\% de la población votó a favor de la separación, que se hizo efectiva el 1 de febrero de 1985, aunque conservó, incluso hasta hoy en día, el estatus de «estado asociado». La CEE perdía con ello el $57 \%$ de su territorio en ese momento, además del libre acceso a los caladeros de aguas groenlandesas, objetivo principal de esta escisión. No obstante, se mantuvo en pie la posibilidad de firmar diferentes tratados con la posterior Unión Europea, así como incorporarse a organizaciones internacionales como el Consejo Nórdico (1984) y el Consejo Ártico (1996). Por otro lado, la prohibición de la CEE sobre la importación de productos derivados de la foca afectó gravemente a la economía groenlandesa, tal y como ya se ha indicado para el caso de la costa este (Bailón 2012: 150, 2015: 390).

Durante los primeros años de Gobierno autonómico, se le fueron transfiriendo numerosas competencias políticas, a excepción de política exterior, justicia, Tribunal Supremo, defensa, seguridad y política monetaria (Bailón 2012: 150; Informante 8). Gran parte de la población danesa, sobre todo aquella con alta especialización laboral, abandonó la isla, por lo que surgieron nuevas instituciones culturales y educativas para formar a los propios groenlandeses. En 1985 se establecía la bandera groenlandesa (Erfalasorput). En 1986 se crearon dos corporaciones, los proeks, a cargo de la compra, procesado y venta de productos groenlandeses, y la KNI (Kalaallit Niuerfiat/Comercio de Groenlandia) pasó a ocuparse del suministro comercial, con una cadena de tiendas estatales, Pilersuisoq SA. Además, se implementaron infraestructuras hídricas, con plantas depuradoras de agua de mar, y la primera central hidroeléctrica en 1993, que permitía no depender en tan gran medida de los generadores eléctricos de gasolina (Bailón 2012: 150-151, 2015: 391-392). El gobierno autónomo groenlandés está invirtiendo en las últimas décadas más del $60 \%$ del dinero público en implementar el sistema de suministro eléctrico sostenible. Actualmente se centran en energías renovables no contaminantes, como las plantas hidroeléctricas, cada vez más eficientes y numerosas (The Official Website of Denmark).

En un primer momento el Gobierno autónomo estableció la pesca industrial como la base del desarrollo económico, con la Royal Greenland $A / S$ a cargo de la gestión de gran parte del sector. Este tipo de pesca industrial se desarrolla sobre todo en los grandes centros urbanos de la costa oeste, mientras que en localidades más pequeñas se utilizan métodos extractivos tradicionales ${ }^{4}$. No obstante, la dependencia de una exportación poco diversificada e importación de prácticamente todos los productos de consumo regular dificulta el mantenimiento sostenible de este tipo de modelo económico, siendo en los últimos años el turismo, y con ello los servicios, el sector cuyo rendimiento económico más se ha incrementado (Bailón 2012: 151-153, 2015: 391; Statistics Greenland).

Desde el inicio del periodo autonómico, los groenlandeses tuvieron que hacer frente a diversos problemas heredados, como las diferencias de clase entre poblaciones inuit y danesas. La riqueza estaba asociada al modo de vida europeo y eso generó una notable pérdida de la identidad cultural local. Esto trajo consigo el surgimiento de nuevos problemas en la segunda mitad del siglo XX, como el elevado número

\footnotetext{
4 Véase por ejemplo el sistema de pesca de bacalao en la costa oeste de Groenlandia estudiado por Santiago D. Domínguez-Solera (2014: 56, 2016: 243-272).
} 
de suicidios juveniles, el alcoholismo, las enfermedades de transmisión sexual o el consumo de drogas. Además, se debió afrontar la elevada cantidad de recursos destinados a la administración, cerca de la mitad de la subvención global procedente de Dinamarca. En cualquier caso, los subsidios gubernamentales eran una parte fundamental para mantener el equilibrio económico (Bailón 2015: 392-393).

La toma de conciencia de esta serie de conflictividades en cuanto a la gestión que se había ido haciendo de los recursos económicos y administrativos, así como de los problemas heredados del contexto colonial, hizo que poco a poco fuera creciendo y consolidándose un pensamiento independentista. A razón de ello, en 1999 se creó una comisión danesa-groenlandesa para trabajar en una propuesta de autogobierno en Groenlandia. Esto también se vio reflejado en los resultados electorales del gobierno autonómico. Si hasta entonces había gobernado en solitario Siumut, socialdemócratas internacionalistas, en 2002 lo hizo en coalición con Inuit Ataqatigiit, partido de corte socialista e independentista inuit, que acabó por gobernar en 2009, con apoyo de Demokratiit y representantes independientes.

Esta victoria del partido independentista está estrechamente relacionada con la situación política groenlandesa en busca del autogobierno. El 25 de noviembre de 2008, era convocada la población electora a votar en un referéndum de ampliación de la autonomía que abriera las puertas a la independencia nacional. Con una participación del 71,96\%, un contundente 75\% de groenlandeses votó «a favor» y un 23,57\% «en contra». Con Jakob Edvard Kuupik Kleist como primer ministro groenlandés y Lars Lokke Rasmussen como primer ministro danés, se iniciaba un nuevo periodo de diálogo democrático, ahora que Groenlandia oficializaba su autogobierno, el 21 de junio de 2009 (Domínguez-Solera 2014: 13; Bailón 2015: 393-395),

Sin embargo, el modelo económico de explotación mineral y de combustibles fósiles presentado por el gobierno de Kleist y la reforma del sistema municipal, hicieron que perdiese numerosos apoyos. De los dieciocho municipios que había en la isla se pasó a cuatro, los actuales: Qeeasuitsup Kommunia, Kommuneqarfik Sermersooq, Qeqqata Kommunia y Kommune Kujalleq (Figura 3). Con esto se pretendía reducir el número de pequeñas poblaciones y estructuras administrativas, así como concentrar a la población en ciudades (Bailón 2015: 396) y cambiar el modelo urbanístico hacia un modelo occidental, incluso con construcciones en altura (Bailón

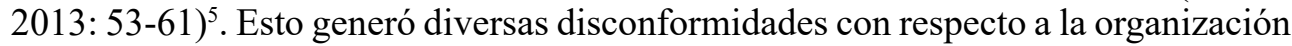
territorial, las necesidades de las poblaciones y su propia identidad, como se verá más adelante.

De la mano de esta reforma, vinieron una serie de políticas que trataban de favorecer la llegada de inversiones de compañías extranjeras para la explotación del subsuelo. Esto podría permitir una mayor recogida de ingresos por parte del gobierno groenlandés, que facilitase la independencia económica. No obstante, vulneraba las leyes de extranjería danesas, pues permitía la implantación de salarios por debajo del mínimo internacional para la mano de obra extranjera. Esto podía afectar notablemente al medio ambiente, los modelos de pesca y caza tradicionales, sin repercutir en demasía en la generación de empleo para la población local, ya que las propias empresas internacionales podrían acudir con sus empleados de salarios bajos. Esto

\footnotetext{
Para conocer mejor la evolución del modelo de residencia inuit y sus cambios conviene reparar en los trabajos y estudios de Francesc Bailón (2013: 31-68). Muchos de los roles tradicionales de las viviendas se han modificado y adaptado a su nueva realidad material (Bailón 2013: 61-66).
} 


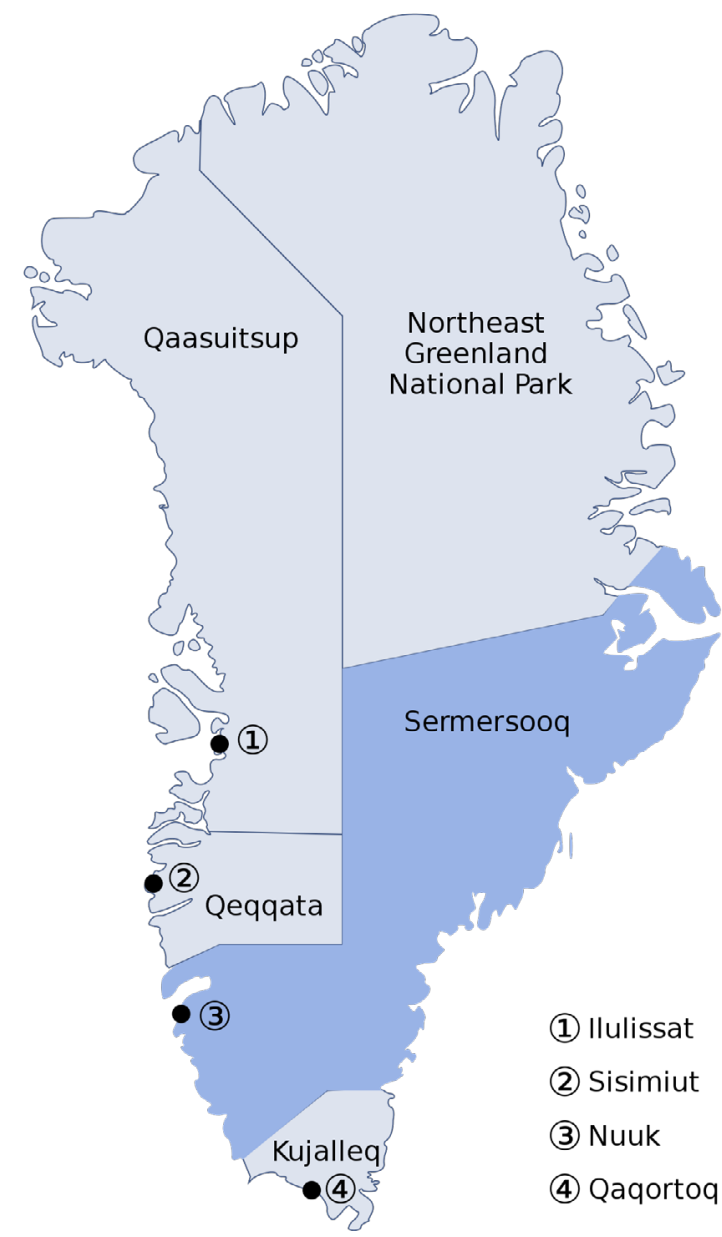

Figura 4. Municipio de Sermersooq, Groenlandia. División administrativa desde 2009, con los centros municipales marcados con números (da.wikipedia.org).

derivó en una fuerte crítica interna que desembocó en la escisión del partido. Nacía así el Partiit Inuit, también independentista, pero en desacuerdo con las lógicas ecologistas y sociales que en un principio correspondían al partido del gobierno (Bailón 2015: 396).

En 2013, Siumut volvió al primer puesto en los comicios, y superó de nuevo a Inuit Ataqatigiit. Aleqa Hammond fue investida como la primera mujer en el cargo de Primera Ministra del país, gracias a su coalición gubernativa con Atassut, de corte conservador, y Partiit Inuit. Las prioridades, junto con la independencia, eran el control de las materias primas por vía impositiva y la limitación de las explotaciones de manera sostenible (Bailón 2015: 396; Greenlandic General Elections 2013, Wikipedia). No obstante, en 2014, un escándalo de gasto afectó a la presidenta, lo que hizo necesaria la convocatoria de elecciones (Greenland calls election amid expenses scandal - The Local Dk) que mantenían en el gobierno a Siumut, pero con Kim Nielsen como Primer Ministro y Ministro de Naturaleza y Medio Ambiente (Naalakkersuisut, Government of Greenland; Greenlandic General Elections 2014, Wikipedia). 
En cualquier caso, pese al ascenso y caída del Inuit Ataqatigiit, primer partido de los declarados secesionistas en llegar al gobierno, el pensamiento independentista ha demostrado estar cada vez más arraigado en la población groenlandesa. Se trata de uno de los objetivos de prácticamente todos los partidos del panorama democrático, con excepción de Demokraatit, de ideología socio-liberal y sustentado principalmente por la población danesa residente en Groenlandia. A pesar de no haber una fecha fijada para la realización de un referéndum que les lleve a la independencia, los diálogos con el gobierno danés están en marcha, incluso se plantea la posibilidad de alcanzar la independencia en la simbólica fecha del 21 de junio de 2021, cuando se conmemorarán los 300 años desde la colonización danesa (Bailón 2015: 394-397). Lo más importante, tanto para los diferentes gobiernos, como para la población, parece ser que el avance sea con paso firme y bases sólidas, que permitan una independencia sostenible (Bailón 2015: 397; Informante 8).

\section{5. ¿Un único modelo de independencia?}

En la actualidad parece que existe un notable consenso entre los residentes de Tasiilaq, de ascendencia inuit o europea, en torno a la posible independencia de Groenlandia con respecto a Dinamarca. Se entienden como realidades nacionales claramente diferenciadas por cuestiones culturales, económicas y políticas, por lo que la emancipación parece la opción más lógica y coherente (Informante 1; Informante 2; Informante 3; Informante 6; Informante 7; Informante 8; Informante 13).

Este pensamiento generalizado tiene una de sus mayores manifestaciones el día 21 de junio, pues la importante celebración inuit del solsticio de verano se ha convertido en el Día Nacional y de él participa toda la comunidad. Reunidos en el pabellón de deportes de la localidad, sustituto contemporáneo de la gran casa comunitaria tradicional o qashe (Bailón 2013: 64), la población nativa, extranjeros residentes y turistas, comparten bebidas y alimentos. Aquí se exponen algunos de los elementos identitarios de la cultura local, como es la realización de duelos de canto y danzas del tambor tradicionales (Figura 4). Este tipo de práctica musical tiene mucha relevancia a nivel social y colectivo como procedente de la herencia de los antepasados y forma parte del aprendizaje tradicional (Informante 10; Informante 11). La música del tambor no se entiende como la de otros instrumentos musicales, con los que se puede alcanzar el virtuosismo a partir del aprendizaje canónico, sino que se trata de un ejercicio personal en el que concentración y corporalidad son fundamentales. Muchas de las canciones tradicionales son relatos del pasado, explicaciones de cómo las cosas han llegado a ser tal y como son ahora. Por todo ello, se trata de un sistema de transmisión del conocimiento intergeneracional y se enseña a los más jóvenes, siempre con la presencia de un adulto, pues no es algo que se pueda aprender en solitario (Informante 11).

El protagonismo central de este tipo de cantos y danzas en la celebración principal y más formal de la fiesta nacional ${ }^{6}$ permite identificar directamente el pasado inuit tradicional con el presente groenlandés. Se manifiesta con ello la especificidad

\footnotetext{
6 Después del discurso de las autoridades culturales locales se realizan cantos tradicionales como parte de la ceremonia formal. Después tienen lugar conciertos y bailes de carácter recreativo con música de tipo occidentalestadounidense (blues, rock, country), pero en un contexto más lúdico y distendido.
} 


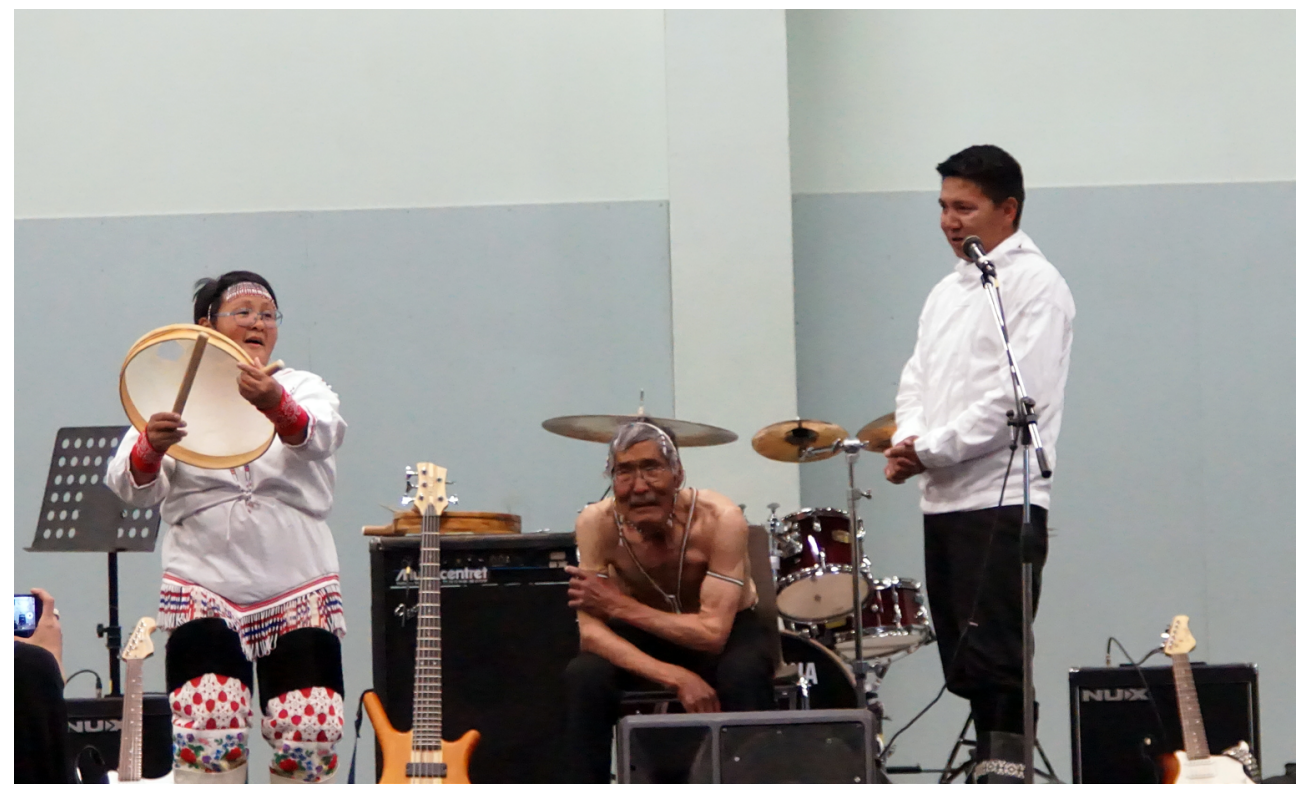

Figura 4. Realización de cantos con tambor tradicionales en la celebración del Día Nacional, 21 de junio de 2017, en el pabellón deportivo de Tasiilaq y vestidos con ropa tradicional regional (fotografía de Carlos Moral García).

de las prácticas insulares como una realidad claramente diferencia del mundo danés europeo. Sin embargo, aquí tiene lugar otra resignificación cultural, pues estas prácticas se realizan con las ropas tradicionales, en concreto las de la costa oriental, de las que se hablará a continuación. Con esto se está poniendo de relieve que Tasiilaq, además de groenlandés, es una localidad de la costa este, diferenciada en algunos aspectos del resto de Groenlandia y, sobre todo, de la costa oeste.

Esta noción parece bastante presente en la población local, que, aunque acepta y comparte la identidad nacional, reivindica la especificidad oriental (Informante 1; Informante 2; Informante 3; Informante 7; Informante 8). No se perciben a sí mismos como el mismo pueblo, pues no tienen el mismo carácter ni las mismas formas de vida, aunque sí que haya algunos rasgos fundamentales comunes (Informante 2; Informante 7). Parte de las poblaciones inuit groenlandesas que no residen en la costa oeste o sur, no se sienten plenamente identificados con el sentimiento nacionalista groenlandés. Desde finales del siglo XX se comenzaron a hacer reclamaciones de derechos específicos sobre los territorios que habitaban, ya que no consideraban que la población de la isla fuera totalmente homogénea y la gestión de los grupos mayoritarios, más occidentalizados, no resultaba satisfactoria (Bailón 2015: 394).

Hay que tener en cuenta que, desde la última reorganización de los municipios, en vigor desde el 1 de enero de 2009, Tasiilaq y la costa este forman parte del mismo municipio que Nuuk, capital nacional ubicada en la costa oeste. Esto lleva a que se realice por parte de la población local una vinculación directa de ambos conceptos. De este modo, no solo se percibe como una parte municipal alejada y diferenciada, sino como el centro nacional, por lo que se identifican políticas autonómicas y nacionales con municipales y viceversa (Informante 13). 
Por ello, hay quien, además de la independencia con respecto a Dinamarca, objetivo básico, aspira a la independencia de la costa este con respecto a Nuuk, de manera que se establezca un autogobierno regional (Informante 7). No obstante, hay personas que, a pesar de reconocer e identificarse con la especificidad y exclusividad de la zona oriental de la isla, no consideran que la emancipación política y sobre todo económica sea posible. Dada la situación ya explicada para todo el caso groenlandés y el caso concreto de la región de Tasiilaq, la dependencia de los sistemas de subsidios estatales y autonómicos es altísima, por lo que no parece conveniente aventurarse hasta la independencia antes de disponer de los recursos necesarios para, al menos, mantener la situación actual (Informante 8). En algunos casos en los que se reclama una mayor autonomía local y mayor capacidad de decisión, se destaca que otros aspectos han mejorado y que, sin las ayudas económicas y materiales externas, ciertas cuestiones de la vida serían mucho más difíciles. Algunas cosas han mejorado gracias a un mayor control gubernamental, sin embargo, otras se han deteriorado ya que antes la toma de decisiones tenía un mayor carácter colectivo y comunitario, lo que permitía satisfacer mejor las necesidades de la población local (Informante 2).

Esto lleva a que la gente considere que a pesar de que en 2009 se decidió comenzar el trámite de independencia de Groenlandia, aún no esté fijada la fecha, puesto que se depende en numerosos aspectos de Dinamarca. Todavía se reciben subsidios daneses por un total de 3,2 billones de coronas danesas (The Official Website of Denmark). Del mismo modo le sucede a la costa este con respecto al gobierno autonómico y municipal de la costa oeste.

Parte de la población considera que esa dependencia regional se podría enfatizar en caso de secesión temprana con respecto a Dinamarca, pues los recursos económicos serían más limitados y aún hay mucha gente que depende de las subvenciones estatales para percibir ingresos suficientes. Parte de la población complementa las subvenciones con trabajos a tiempo parcial o prácticas económicas informales, como la venta de arte no registrada. La mayoría de los residentes de Tasiilaq ha ido modificando las formas de subsistencia tradicional para depender en gran medida de los productos importados que se adquieren a través de las tiendas y supermercados. Entre ellos destaca la cadena Pilersuisoq SA, propiedad del gobierno groenlandés para abastecer todas las localidades. La caza y la pesca, al contrario que en la costa oeste, tal y como se ha explicado, no tienen un papel económico central, sino que se trata de una práctica complementaria, tanto para el consumo como para la venta. En general, la dependencia de los productos importados hace que se desarrolle también una cierta dependencia económica con respecto a ayudas e infraestructuras para poder costear una nueva forma de vida a medio camino entre el modelo tradicional y el occidental (Informante 8).

No obstante, el sistema de partidas presupuestarias con municipios de gran tamaño, como Sermersooq, que deben responder a problemáticas diferenciadas en una costa y en otra, parece generar problemas y disconformidad en el caso oriental. En ocasiones esta forma de toma de decisiones no puede satisfacer ciertas necesidades, ya que en caso de surgimiento de imprevistos la redirección de los recursos económicos puede ser algo complicada (Informante 8; Informante 13). Por ello, hay quien reclama una mayor autogestión política y una toma de decisiones local, para poder satisfacer necesidades puntuales que ahora no parecen cubiertas (Informante 1; Informante 7). Sin embargo, si para conseguir ese nivel de autogobierno es necesario 
establecer un sistema de autoabastecimiento económico y material, podría ser aún más grave para la población dadas las condiciones de la costa este (Informante 8).

En cualquier caso, esta situación lleva a que parte de la población haya establecido una asociación directa entre la costa oeste y los procesos de «groenlandización» nacional. La no satisfacción de ciertas necesidades materiales por parte del sistema de municipios da una idea de deslocalización en la toma de decisiones, que se puede identificar con un modelo de centralización en la costa oeste, por ser la capital nacional y tener más recursos económicos. Por ello, es constante la reivindicación de la especificidad cultural de la costa este, lo que se manifiesta en gran medida a través del arte tradicional.

\section{Arte tradicional: comercio e identidad}

Hablar de arte tradicional inuit supone inexorablemente hacer referencia a las estatuillas tupilait (tupilak en singular) (Figura 5). En el pasado se trataba de objetos de pequeño tamaño, realizados siempre por expertos y especialistas rituales, ya fueran ângakoq o ilisîtsop ${ }^{7}$. Eran un elemento estrechamente asociado con las prácticas de tipo mágico y/o religioso y se destinaban a infringir daño a los enemigos (Kleivan, Inge 1984: 619-620; Mary-Rousselière 1984: 441; Petersen 1984a: 632; Jensen 2011: 5; Bailón 2012: 83; Domínguez-Solera 2014: 106). En otras ocasiones tenían carácter apotropaico, tanto para su portador, como para la comunidad (Bailón 2012: 83; Haagen 2014: 8-9).

Originalmente el tupilak tenía formas más sencillas que en la actualidad, aunque se solían realizar con varios materiales diferentes, generalmente restos animales o incluso humanos, que debían pasar por un proceso ritual antes de su composición como una nueva forma viva. Se dejaban atados durante un tiempo en un lugar secreto y apartado que solo conocía el especialista ritual. Llegado cierto momento debía proceder a darles forma, pero solo utilizando los meñiques y pulgares. Era bastante habitual que tomase un aspecto monstruoso, de rasgos antropomorfos o zoomorfos, aunque no demasiado complejo. El especialista permitía que este nuevo ser construido tomase poder de sus genitales para crecer. Tras esto, este espíritu materializado podía ser enviado por mar para atacar y eliminar a los enemigos (Kaalund 2001: 190-191; Gitz-Johansen 2009: 61-65; Jensen 2011: 5; Haagen 2014: 8). No obstante, si el adversario demostraba tener un poder mayor que el del primer conjurador podría ser capaz de devolverlo, incluso con una carga mayor de poder ritual dañino (Larramendi 1995:101; Kaalund 2001: 190-191; Jensen 2011: 6). En este proceso de creación de un nuevo ser espiritual era fundamental la participación del chamán, que trabajaba guiado por los espíritus (Informante 2); una vez terminado su cometido, esta criatura desaparecía como ser animado y perdía todo su poder ritual (Kaalund 2001: 190-191).

Sin embargo, esta faceta ritual parece ser solamente cosa del pasado, pues ahora estos objetos son, por encima de todo, arte (Informante 2; Informante 9). Como se ha dicho, los materiales originales tenían normalmente origen orgánico y eran no-

\footnotetext{
En muchas ocasiones se identifica al ângakoq como chamán, por tratarse del especialista ritual y religioso reconocido y aceptado por la comunidad; el ilisîtsop por su parte tiene connotaciones negativas, pues a pesar de presentar poderes similares tiene un carácter egoísta y malintencionado (Moral-García 2017: 16).
} 
Figura 5. Tupilait talladas en asta de caribú (fotografía de

Carlos Moral García).

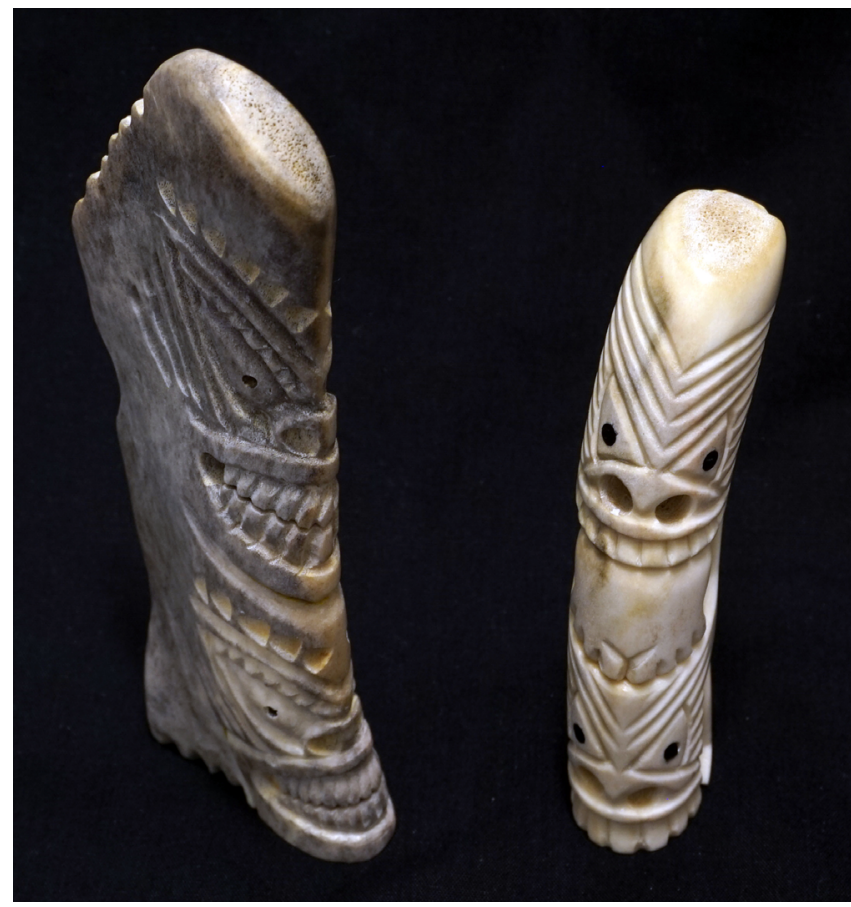

tablemente perecederos, de modo que se han conservado pocos hasta la actualidad. $\mathrm{Su}$ poder ritual y la noción de ser de un solo uso les convertía en objetos efímeros que se destruían una vez se habían cumplido los objetivos iniciales. La mayoría de los ejemplos etnográficos y museísticos son reproducciones talladas en madera por la población inuit para explicar a los primeros extranjeros cómo funcionaban estos objetos-espíritus. Poco a poco se fueron incorporando otros materiales, como piedra, hueso, marfil o asta de caribú, ya que, al llamar mucho la atención de los visitantes, se convirtió en un objeto susceptible de venta o intercambio por productos europeos (Jensen 2011: 6).

Antiguamente es posible que los tupilait de la costa oeste y la costa este fueran bastante diferentes, pero con el paso del tiempo y su conversión en un objeto artístico comercial se han ido asimilando formas parecidas en diferentes regiones (Jensen 2011: 6; Haagen 2014: 11). Cuanto más grotesco y aterrador más fácil resultaba su venta (Jensen 2011: 6), por lo que comenzó a generarse una corriente artística que aprovechaba complejas composiciones con formas animales y humanas para mostrar la habilidad del artista (Blodgett 2001: 113-114; Jean Ray 2001: 42; Kaalund 2001: 210-211; Informante 2). Los propios autores dicen ser influidos por sus predecesores y por las obras de sus compañeros, ya sean de la costa este u oeste e incluso Canadá (Informante 2). Este proceso de creación artística ha perdido sus connotaciones rituales para ser un objeto artístico de mercado inserto en un sistema capitalista global. Se ha generado un modelo estereotipado de tupilak como obra de arte inuit.

Sin embargo, aunque todo el arte tradicional es ahora susceptible de venta, ya que se trata de una de las fuentes de ingresos fundamentales asociadas al sector turístico, no todo ha pasado a ser una versión estereotipada a nivel nacional o etnocultural. En Tasiilaq, gran parte de la producción artística y artesanal es específicamente regional 


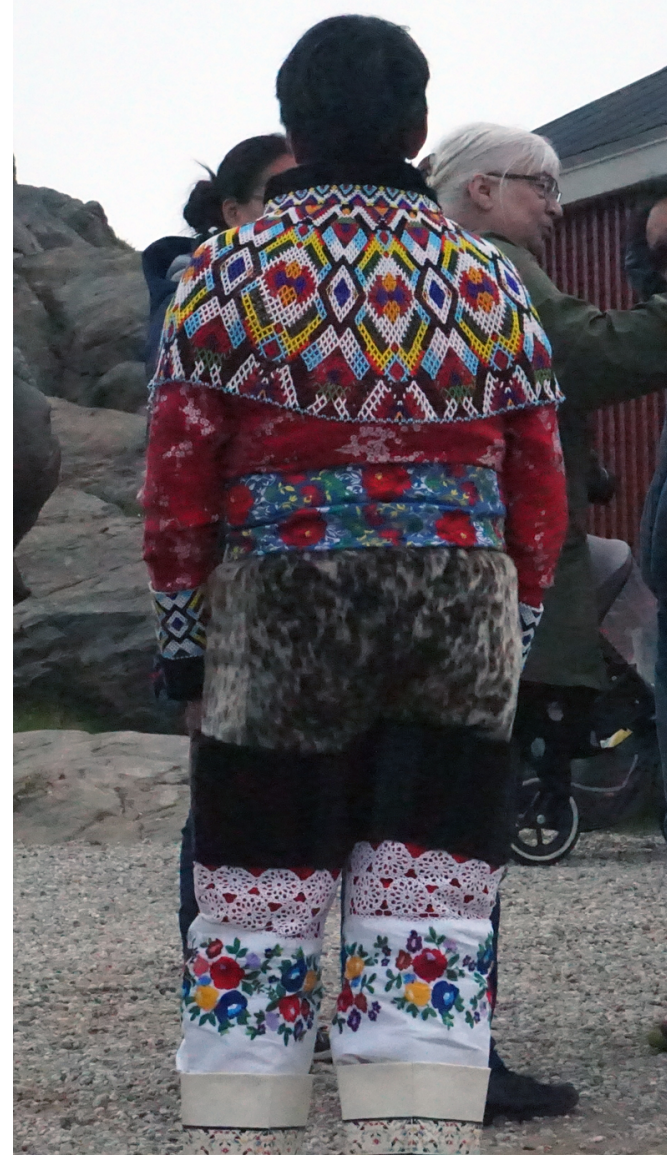

Figura 6. Traje nacional femenino groenlandés originario de la costa oeste (fotografía de Carlos Moral García).

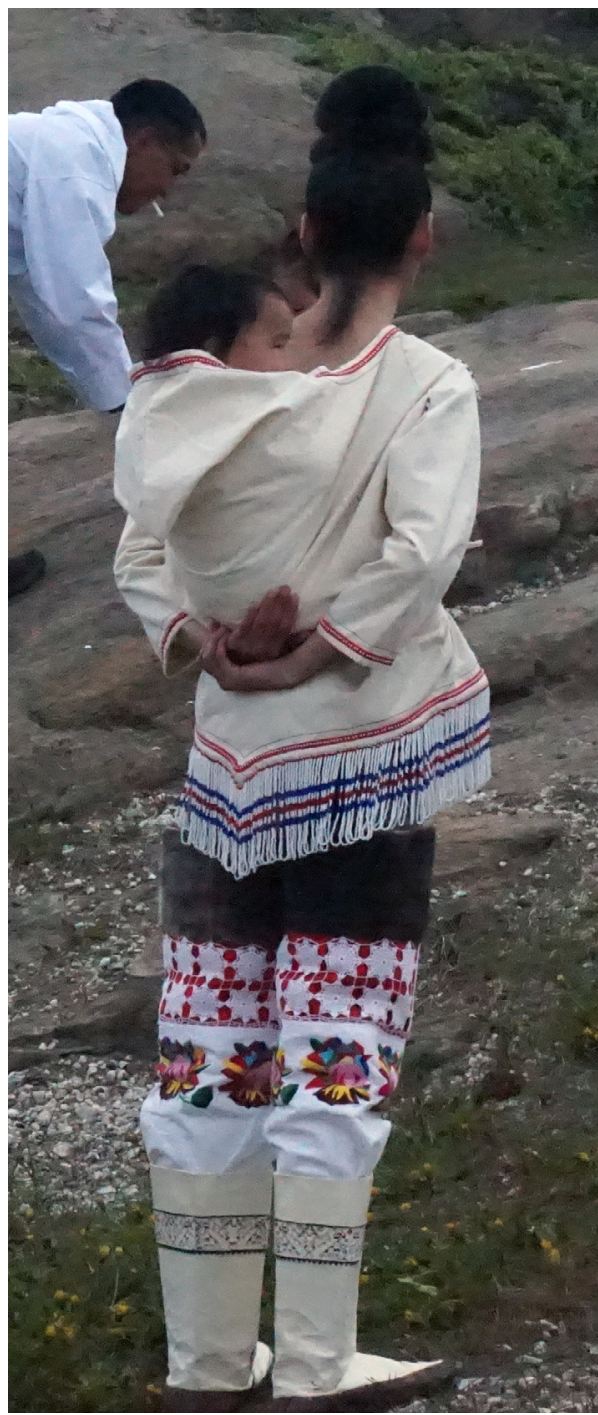

Figura 7. Amaat o traje tradicional femenino de la costa este (fotografía de Carlos Moral García).

y así lo hacen saber los autores de las obras en el momento de la venta (Informante 2; Informante 5; Informante 9).

Esto resulta evidente con un elemento tan llamativo y visible como es el traje tradicional para celebraciones. El modelo que en Tasiilaq se percibe como propio de la costa oeste (Figura 6), con vivos colores y complejas decoraciones, se ha convertido a menudo en un signo de identidad nacional, incluso en un reclamo turístico para el mercado internacional. Sin embargo, la población local reclama y reivindica el uso de su amaat (Figura 7), traje tradicional femenino, pues la identificación del oeste con la totalidad de la nación inuit groenlandesa invisibiliza la realidad de la costa este. El traje de esta región es muy sencillo, originalmente de piel, aunque ac- 
tualmente de algodón, pero siempre de color claro, prácticamente blanco (Kaalund 2001: 192-193; Jensen 2011: 3033). Tiene una decoración de cenefas bastante sencillas en sus bordes, lo que se complementa con collares de cuentas y pulseras con motivos geométricos entre los que predominan los colores blanco, rojo y azul (Jensen 2011: 3033; Informante 6). En diversas regiones árticas se pueden encontrar variaciones de este tipo de vestimenta, tanto en color como en estilo y patrones de corte y adorno.

El traje tradicional masculino se compone de un anorak (Figura 8) más modesto y con menos decoración. Evidentemente, a pesar de su sencillez, existen variaciones regionales en lo que a los patrones de corte se refiere y no es conveniente hablar de un único anorak. En el caso oriental se trata de una prenda blanca, en la que se ha sustituido la piel por el algodón. Además, viene complementado con unos pantalones negros y unas botas de piel llamadas kamik (Jensen 2011: 33).

Estas prendas son utilizadas en las ceremonias de canto tradicional, tal y como se ha dicho, pero además en los momentos especiales de celebración familiar, como pueden ser bautizos o confirmaciones cristianas, en este caso luteranas. Es la prenda de etiqueta por excelencia, aunque parte de la población esté adoptando los trajes de estilo europeo para los eventos formales. También, dada la movilidad de población es posible encontrar residentes en

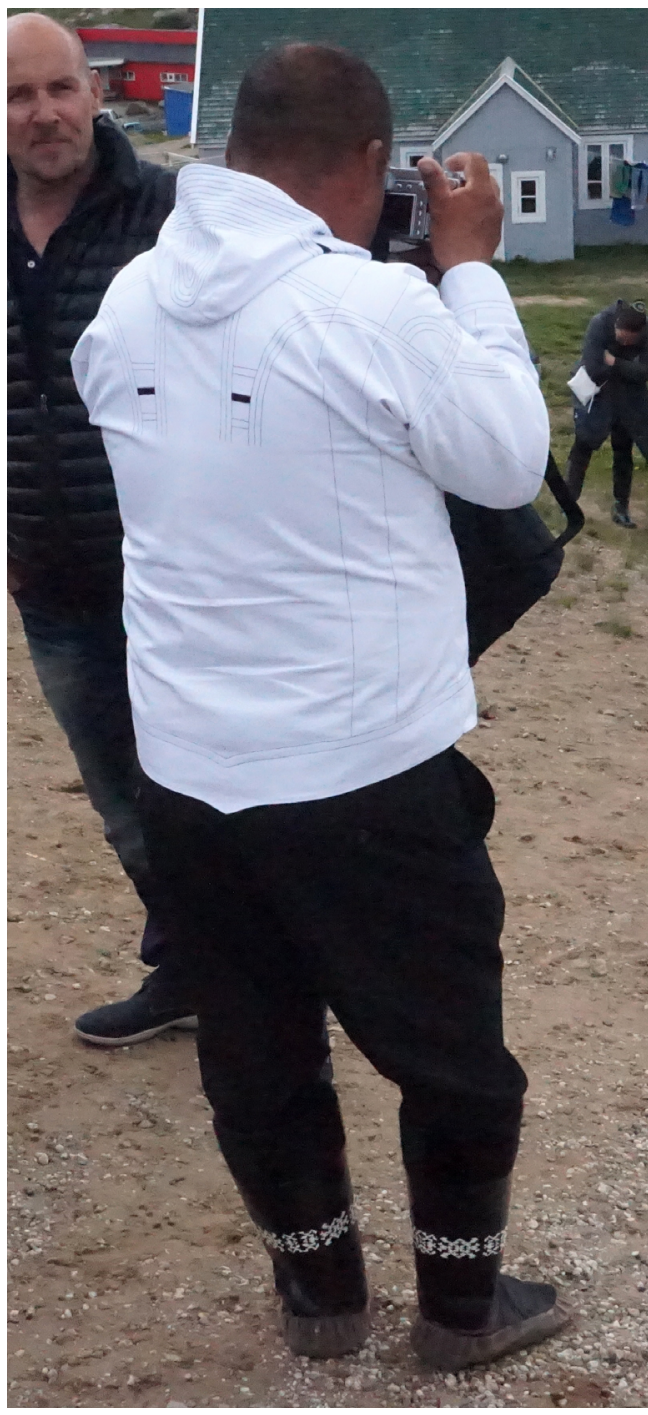

Figura 8. Traje tradicional masculino de la costa este. Anorak blanco, pantalones negros y botas de piel o kamik (fotografía de Carlos Moral García). la costa oriental procedentes de la costa oeste, de modo que visten el colorido traje occidental. No obstante, con este gesto de elección del traje específico regional se está visibilizando la especificidad de la costa este en las grandes celebraciones públicas y los actos comunitarios.

Por otro lado, entre los objetos de cultura material especialmente llamativos como producción artística o artesanal de carácter identitario, y con un gran público turístico, se encuentra el cuchillo de las mujeres. En la costa oeste y en Canadá se conoce a esta herramienta como ulu (Figura 9), mientras que en la costa este, donde se encuentra Tasiilaq, se denomina tsakkeq (Figura 10) (Kaalund 2001: 192-193; 


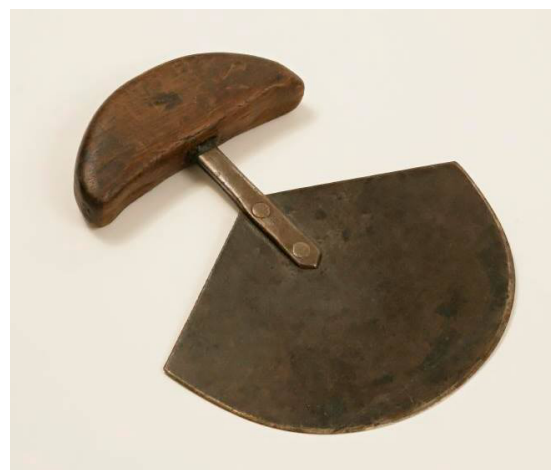

Figura 9. Ulu de Arviat, Nunavut, Canadá, obra de Susan Ootnoojuk (Museo Nacional de Antropología, Madrid; fotografía de Pablo Linés Viñuales).

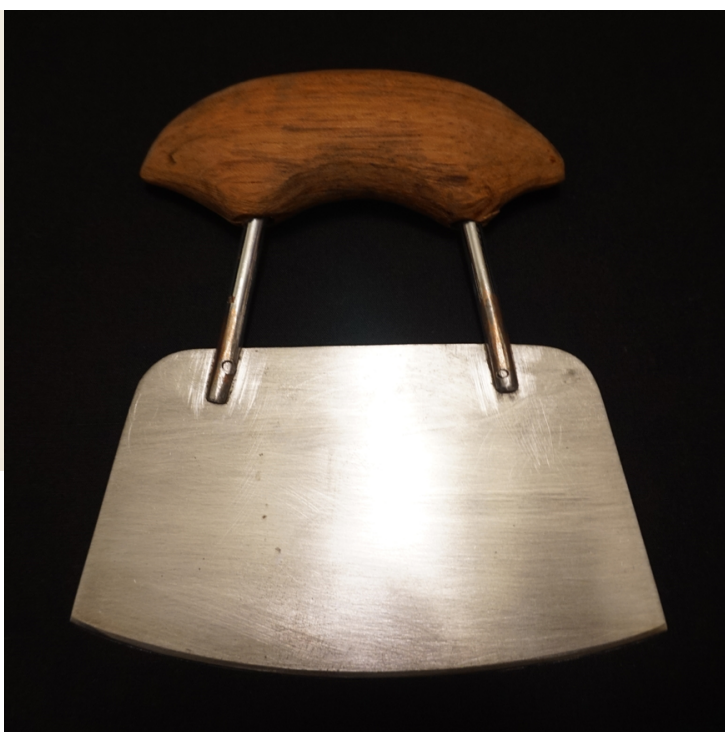

Figura 10. Tsakkeq de Tasiilaq, costa este de Groenlandia (fotografía de Carlos Moral García).

Jensen 2011: 35; Informante 2; Informante 5; Informante 8; Informante 9). Desde la introducción del metal en el mundo inuit, este utensilio femenino consistía en una hoja ancha en forma de media luna, con un asa o mango en la parte superior. Parece tratarse de un heredero directo de los raspadores de piedra del Paleolítico ártico a los que se añadió un trozo de hueso o madera a modo de mango. Se trataba de una herramienta universal, dedicada sobre todo al troceado de la carne y trabajo de las pieles para confeccionar vestimentas, aunque también se podía utilizar para otras funciones, tal y como sucede incluso en la actualidad en algunos hogares groenlandeses (Kaalund 2001: 192-193; Jensen 2011: 35).

Es importante destacar que no existe un único tipo de cuchillo femenino para todo el Ártico americano, pues existen pequeñas variaciones en su forma y manejo, por lo que es conveniente dar prioridad a las denominaciones locales. En el caso del tsakkeq se puede encontrar una hoja más recta y rectangular que en sus homólogos occidentales (Petersen 1984a: 630; Jensen 2011: 35; Informante 2). No obstante, la diferencia más llamativa es la presencia de dos vástagos para unir el asa con la hoja, en lo cual hace mucha incidencia la población local e insiste en que no debe confundirse con el $u l u$ (Petersen 1984a: 630; Informante 2; Informante 5; Informante 9). Esto hace de este cuchillo, además de un marcador de genero tradicional entre la población inuit, un marcador de identidad cultural regional en los inuit contemporáneos.

Es muy posible que esta diferenciación en la forma de la hoja se deba a los diferentes tipos de metales accesibles en un primer periodo colonizador de contacto con los europeos. Si bien en Canadá, Alaska y el oeste de Groenlandia se fabricaban las hojas recortando diferentes elementos metálicos disponibles, como serruchos, en el este parece que se debieron de usar los flejes de barriles arrastrados por la corriente, de modo que se optó por hojas rectangulares (Jensen 2011: 35-36). Actualmente el origen de los metales ha variado ligeramente. En las zonas 
occidentales de Groenlandia se pueden encontrar hojas de $u l u$ fabricadas solo con este fin, sin embargo, en las regiones norte y este, suele tratarse de materiales reciclados de otros objetos europeos de uso cotidiano (Jensen 2011: 36; Informante 8). La mayoría de las hojas de tsakkeq están hechas a partir de hojas de sierra de carpintería, así como la madera del mango puede venir de tablas compradas con este único objetivo o de pedazos de mobiliario de madera (Informante 2; Informante 9).

Esto hace necesario reparar en los métodos de fabricación y aprendizaje de los artistas groenlandeses. En general, se comienza a aprender este tipo de prácticas desde una edad muy temprana, entre los 4 y 10 años, para así saber diferenciar a la perfección los materiales válidos para cada obra y los matices que se pueden encontrar entre los huesos, colmillos, cuernos y astas de los animales del Ártico (Informante 2). Pero además se debe aprender a utilizar las herramientas que, aunque están dedicadas al arte tradicional, son totalmente contemporáneas. Se hace uso de maquinaria eléctrica de tipo industrial, como pueden ser las pulidoras de mesa y de mano que facilitan hacer un trabajo rápido a la par que preciso (Informante 2; Informante 4).

Dado que se trata de una forma de obtener recursos económicos complementarios y casi siempre externos, la producción y venta de obras de arte es algo fundamental para la comunidad. Las propias redes de abastecimiento municipal y autonómico facilitan el acceso a materiales como astas de caribú (Rangifer tarandus) y los cuernos y huesos de buey almizclero (Ovibos moschatus) a pesar de que no habitan el área circundante a Tasiilaq. Esto se debe a que son los únicos materiales animales sin ningún tipo de limitación en su exportación. Así se facilita su venta a turistas, pues de otro modo necesitarían certificaciones de que proceden de animales cazados de manera acorde con las tasas fijadas (Informante 2; Informante 8).

Tal y como se puede observar a través de sus métodos de producción, con un artista individual para cada pieza completa, pero utilizando la tecnología disponible para acelerar el proceso, la productividad de cara a su venta es cada vez más importante. En ningún momento se establece una cadena productiva al estilo «fordista» que, aunque podría ser más eficiente, despojaría a las piezas de su categoría de «obras de arte individualizadas». Lo más importante no es el mantenimiento de la fabricación al estilo tradicional, sino la creación de productos acabados que respeten la forma y el concepto tradicional local.

A su vez, el mantenimiento de estas fisionomías artísticas locales, y no el recurso a un arte inuit o groenlandés estereotipado, como sí sucede con los tupilait, permite de nuevo la reivindicación de la identidad específica. Esto genera una dualidad en los tipos de producción artística. Por un lado, un antiguo objeto ritual, por su especial interés para los visitantes extranjeros, ha pasado a convertirse en un objeto de tipo nacional e incluso etnocultural genérico. Mientras tanto, otros objetos, más cotidianos y menos llamativos, como las ropas y algunos utensilios, han mantenido su carácter local. La creación y venta de productos identificados como puramente locales genera y mantiene la propia identidad y especificidad regional que los productos estereotipados pasan por alto. Con esto, parte de la producción artística se ha convertido en una carta de presentación de las particularidades de la costa este ante un mundo capitalista y occidental homogeneizador y reduccionista, principal consumidor de este arte. 


\section{Conclusiones}

Este trabajo de repaso histórico y etnográfico parece confirmar la propuesta de Eric Wolf (1983: 3-7) que afirma que resulta imposible realizar etnografías de campo en un contexto libre del contacto e influencia colonial y/o capitalista por la propia naturaleza de esta disciplina. Eso no quiere decir que no se pueda realizar trabajo etnoarqueológico para conocer mejor las sociedades y culturas predecesoras de las estudiadas, mediante el análisis de los elementos persistentes. Pero, desde luego, la revisión de los fenómenos de contacto y colonización es fundamental para poder realizar tal estudio, teniendo en cuenta los cambios además de las persistencias.

En el caso groenlandés es fundamental entender el proceso de colonización y la progresiva occidentalización, para poder comprender mejor la situación contemporánea de la isla. La población nativa vio modificadas sus formas de vida por la introducción de nuevos recursos materiales, algunos de gran utilidad para la subsistencia, pero también otros desintegradores del modelo de vida tradicional. La caza y pesca no industrial, del mismo modo que el arte, parece que siguen manteniendo las mismas lógicas personales pese a utilizarse nuevas herramientas, como las armas de fuego y la maquinaria eléctrica respectivamente. Esto supone la generación de dependencia con respecto a productos importados para la explotación del medio, que, si bien no es de manera puramente tradicional, tampoco se trata de una producción industrial.

La pesca industrial en la costa oeste de Groenlandia es uno de los sectores que más empleo y dinero genera, al contrario que en el este. Eso ha hecho que la costa occidental haya podido generar más recursos económicos para la creación de infraestructuras e importación de diferentes productos que han pasado a convertirse en básicos. Actualmente, en los núcleos de población de mayor tamaño es fundamental el papel de las importaciones y los supermercados de cara a la subsistencia, pues caza y pesca no industrial han tomado una posición complementaria. Por ello, la generación de empleo y capital por parte de todo tipo de industrias y servicios es algo clave para el desarrollo de estos centros urbanos, como es el caso de Tasiilaq.

Durante largo tiempo el binomio riqueza-europeos estuvo vigente en este territorio. Esto supuso un desarrollo económico e infraestructural a ritmos diferentes en cada región, dependiendo de los negocios e intereses desarrollados por la población extranjera en tierra groenlandesa. No hay más que ver el desarrollo de la actual Tasiilaq, cuyo origen como núcleo urbano viene de la mano de un puerto de intercambio danés. Del mismo modo, la costa oeste de la isla, con mayor afluencia de población metropolitana en tiempos coloniales, por estar bañada por corrientes de aguas más cálidas y por su posición estratégica a las puertas del paso del noroeste, ha experimentado un mayor desarrollo económico dentro de las lógicas occidentales de un mercado global. Una vez generadas esas diferencias infraestructurales de tipo regional, llegaron a ser incluso asumidas por parte de la población autóctona, lo que generó nuevas realidades diferenciadas que combinan el pensamiento tradicional y las nuevas materialidades a su alcance.

Por otro lado, se asistió a una progresiva descolonización política que pasaba por la realización de un proceso de «desdanesificación» para lo que se procedió a una «groenlandización». Esta nueva corriente tomó ciertos rasgos culturales específicos regionales como si de elementos generales y nacionales se tratase, como es el caso de los trajes tradicionales o los cuchillos femeninos. Esta serie de movimientos 
políticos y culturales fueron muchas veces encabezados desde la costa oeste, pues se trata ante todo de procesos de carácter democrático, asumiendo el sistema político occidental. Solo desde esta región podía acometerse tal empresa por ser la más occidentalizada y rica, sin embargo, eso generó ciertas disconformidades, siempre dialogantes, en otras regiones.

A esto hay que añadir la reordenación del sistema municipal, pues, aunque a priori unificar una de las regiones económicamente más ricas, como Nuuk, con otras más tradicionales y pobres, como las de la costa este, podría servir para compensar esas desigualdades, el resultado no parece haber sido satisfactorio. En la población de Tasiilaq parece que se asume como una forma de externalización de la toma de decisiones políticas locales, lo que genera descontento.

Tampoco conviene pensar que esto esté generando enfrentamientos o conflictos más allá del diálogo político y democrático, muy lejos de las encendidas discusiones en otros contextos. El modelo de comportamiento que Groenlandia ha asumido para su proceso de independencia con respecto a Dinamarca fija como objetivo último la emancipación, pero no antes de que sea sostenible económicamente, ya que pasa a insertarse en el mercado global como un estado propio. Se podría pensar que el proceso a seguir por la costa este podría llegar a ser similar, aunque por el momento esté lejos de suceder y simplemente se esté procediendo al mantenimiento de los elementos de identidad regional.

Por ello, no es casual que la producción artística se haya convertido en uno de los elementos principales de estas dinámicas de resignificación identitaria. En primer lugar, por las diferencias fácilmente apreciables que se encuentran en este tipo de elementos. Pero, además, la autogestión política y económica de las regiones orientales de Groenlandia, pasa, al menos en el pensamiento de la población actual, por el desarrollo del sector turístico. El aumento de estas actividades, con consumidores diferentes a los primeros visitantes de la isla, que tenían especial interés por el exotismo, permite que las formas de arte menos llamativas, pero no estereotipadas tengan una mejor acogida y venta. De esta manera, la producción artística es mucho más que una fuente de ingresos en un contexto dependiente del turismo, pues permite, sobre todo, mantener una serie de rasgos culturales y visibilizarlos ante un mundo global.

\section{Referencias}

Bailón Trueba, Francesc. 2012. Los poetas del Ártico. Historias de Groenlandia. Sevilla: Guadalturia Editores.

—. 2013. «Del iglú a las casas prefabricadas inuit». Anales del Museo Nacional de Antropología XV: 31-68.

- 2015. Los inuit: cazadores del Gran Norte. Barcelona: Nova Casa Editorial.

Blodgett, Jean. 2001. «L'art inuit du Canada», en L'art du Grand Nord, Jean Malaurie, dir., pp. 95-157. París: Éditions Citadelles \& Mazenod.

Christensen, N.O. y Hans Ebbesen. 1984. Angmagssalik itsak - i gamle dage. Copenhague: Arktisk Institut. Publikationer.

City Population. Greenland-Kalaallit Nunaat. http://citypopulation.de/Greenland.html.

Damas, David, ed. 1984. Handbook of North American Indians. Vol. 5 Arctic. Washington, D.C.: Smithsonian Institution Press.

Denmark, The Official Website of. http://denmark.dk. 
Domínguez Solera, Santiago D. 2014. Los inuit. Caza y pesca en el oeste de Groenlandia. Cuaderno de campo. Madrid: Clan Editorial.

—. 2016. «Etnoarqueología y el mar en el oeste de Groenlandia: varios apuntes útiles sobre la pesca del bacalao», en El mar: una forma de vida en América, Alberto HocesGarcía y Carlos Moral-García, coords., pp. 243-272. Madrid: Historia y Cultura del Mar. Gad, Finn. 1984. «History of Colonial Greenland», en Handbook of North American Indians. Vol. 5 Arctic, David Damas, ed., pp. 556-576. Washington, D.C.: Smithsonian Institution Press.

Gitz-Johansen, Jeppe. 2009. Figurer $i$ Gronlansk Mytologi/Characters of the Greenland Mythology/Kalâtdlit ugpersisatoqaisa inugtaisa ilait. Skjenn: Gullanders Bogtrykkeri.

Haagen, Birte. 2014. Tupilaks. Magical figures from Greenland. Agernvej: Tinok.

Jean Ray, Dorothy. 2001. «L'art esquimau-aléoute d'Alaska», en L'art du Grand Nord, Jean Malaurie, dir., pp. 23-93. París: Éditions Citadelles \& Mazenod.

Jensen, Ole G. 2011. Destellos de la cultura de Groenlandia. Clemenstrykkeriet: Milik Publishing.

Kaalund, Bodil. 2001. «L'art du Groenland», en L'art du Grand Nord, Jean Malaurie, dir., pp. 159-223. París: Éditions Citadelles \& Mazenod.

Kleivan, Helge. 1984. «Contemporary Greenlanders», en Handbook of North American Indians. Vol. 5 Arctic, David Damas, ed., pp. 700-717. Washington, D.C.: Smithsonian Institution Press.

Kleivan, Inge. 1984. «West Greenland Before 1950», en Handbook of North American Indians. Vol. 5 Arctic, David Damas, ed., pp. 595-621. Washington, D.C.: Smithsonian Institution Press.

Larramendi, Ramón Hernando de. 1995. Los indios esquimales. Colección Pueblos y Lenguas Indígenas 6. Quito: Abya-Yala.

Mary-Rousselière, Guy. 1984. «Iglutik», en Handbook of North American Indians. Vol. 5 Arctic, David Damas, ed., pp. 431-446. Washington, D.C.: Smithsonian Institution Press.

Moral García, Carlos. 2017. «Acercamiento a la ontología y cosmología inuit tradicional: de los 'inue' al 'ângakoq'», en Naveg@mérica. Revista electrónica editada por la Asociación Española de Americanistas 18. https://revistas.um.es/navegamerica/article/ view/286401.

Naalakkersuisut, Government of Greenland. http://naalakkersuisut.gl.

Petersen, Robert. 1984a. «East Greenland before 1950», en Handbook of North American Indians. Vol. 5 Arctic, David Damas, ed., pp. 622-639. Washington, D.C.: Smithsonian Institution Press.

- 1984b. «East Greenland After 1950», en Handbook of North American Indians. Vol. 5 Arctic, David Damas, ed., pp. 718-723. Washington, D.C.: Smithsonian Institution Press.

Robert-Lamblin, Joëlle. 1986. Ammassalik, East Greenland - end or persistance of an isolate? Anthropological and demographical study on change. Collection Man \& Society 10. Copenhague: Museum Tusculanum Press.

Statistics Greenland. http://www.stat.gl.

The Local Dk. http://www.thelocal.dk.

Wolf, Eric R. 1983. Europe and the People without History. Berkeley y Los Ángeles: University of California Press. 